\section{Hoe om die Bybel beter te verstaan: Verklarings van die Bybel in Afrikaans}

W Vosloo

(Universiteit van Pretoria)

\section{ABSTRACT}

\section{A better understanding of the Bible: Bible Commentaries in Afri- kaans}

During the early 1920's some sporadic (and experimental) commentaries on the Bible in Afrikaans were published. However, after the Bible was translated into Afrikaans in 1933 these drops turned into a stream and soon swelled into a torrent of publications. These publications display a steady growth in Biblical understanding from a literal and even fundamentalistic interpretation to a critical exegesis of Scripture. At least three distinct phases can be demonstrated, namely a focus on the author, then on the text, and finally on the reader. Given the limited number of readers, the publication of Afrikaans commentaries in the future is faced with unique problems and decisions.

\section{INLEIDING}

Die vraag hoe die mens die Bybel beter kan verstaan, is 'n oer-oue vraag. Trouens, verklarings van die Bybel is onlosmaaklik van die Bybel self. Dit het vanaf die vroegste tye deel gevorm van die verstaans- en interpretasieproses van die Bybel. Reeds in Deuteronomium 1:5 lees ons dat "Moses die wet begin verduidelik het" en Nehemia 8 gee 'n uitvoerige beskrywing van hoe Esra die "wetboek van Moses" voorgelees en die Leviete dit aan die volk verduidelik het.

\section{KOMMENTARE IN AFRIKAANS}

Afrikaanssprekendes moes vir baie lank staat maak op die verklarende aantekeninge van die ou Hollandse Statenvertaling. Met die verskyning van die Bybel in Afrikaans in 1933 was dit dus 'n noodwendige behoefte om ook te vra na 'n Afrikaanse verklaring daarvan. Alhoewel daar vóór die verskyning van die 1933-vertaling enkele pogings tot verklaring was (kyk by "CSV-reeks" hieronder), word hier veral gekonsentreer op kommentaar-reekse en Bybels met verklarende aantekeninge ná die publikasie van die Bybel in Afrikaans.

\subsection{Die "CSV-reeks" (vanaf minstens 1923)}

Die CSV Boekhandel in Stellenbosch het gedurende die twintiger- tot vyftigerjare verskeie kommentare op die Bybel gepubliseer. Sommige van hierdie publikasies se datums is onbekend, maar waarskynlik een van die oudstes is N J van der Merwe se Die brief van Paulus aan die Romeine in 1923. Ander skrywers is: A B du Preez se Die brief van die apostel Paulus aan die Romeine (Rom 1-9, s.j.), H D A du Toit en D Oosthuizen se Daders van die Woord (verklaring van die Brief van Johannes, 1946) en G D du Toit se Brief aan die Efesiërs (1951). Sommige van hierdie kommentare soos G D du Toit se s'n op Efesiërs dui op deeglike navorsing en gebruikmaking van die werk van bekende kenners van destyds.

\subsection{Die "Swartband reeks" (vanaf 1944)}

Die "Federale Raad vir die Kerke" het in die vroeg-veertigerjare opdrag gegee dat daar onder redaksie van sy Kommissie vir Bybelverklaring 'n reeks kommentare op die Bybel geskryf moet word (Groenewald 1967:"Voorwoord"). Die reeks het bekend gestaan as Kort Verklaring van die Heilige Skrif vir die Afrikaanse Volk. Van die heel eerste publikasies is J F Mentz se Die Brief aan die Efesiërs (Suid-Afrikaanse Bybelvereniging, 1944), G B A Gerdener se Die Evangelie van Mattheus" (SA Bybelvereniging, 19--), J H J Greyvenstein se Die Openbaring van Johannes (NG Kerk-Uitgewers, 1957) en F C Fensham se Die brief aan die Hebreërs (NG Kerk-Uitgewers, 1962, hersien in 1981).

Met die tot standkoming van die Algemene Sinode is voortgegaan met die publikasie van kommentare, maar nou sonder 'n naam. Sommige uit die era van die "Kort Verklaring" is vervang met kommentare deur nuwe skrywers. Dit is mettertyd nie-amptelik die "Swartband-reeks" genoem. 'n Groot aantal publikasies van die NG Kerk-Uitgewers het gaandeweg die lig gesien, waarvan E P Groenewald se Die Eerste brief aan die Korinthiërs (1967) en W D Jonker se Die brief aan die Romeine (1967), Adrio König se Die profeet Amos (1974) en W S Prinsloo se Die boek Rut (1982) enkele voorbeelde is. Omdat daar geen spesifieke voorskrifte gemaak is nie, vertoon die kommentare 'n verskeidenheid eksegetiese invalshoeke en uiteenlopende styl.

Teen die einde van die tagtigerjare het die uitgewers besluit om die reeks 'n amptelike naam te gee, naamlik: Skrifuitleg vir Bybelstudent en Gemeente. Die eerste publikasie met hierdie opskrif is PA Verhoef se Die Boek Haggai (1989). Daarna het verskeie ander ook verskyn. Die reeks dek egter nog nie die hele Bybel nie. Daar word beplan om die ontbrekende kommentare op elektroniese skywe beskikbaar te stel.

Omdat hierdie reeks 'n lang wordingsgeskiedenis het, verskil die uitlegmetodes ook grootliks. Dit blyk byvoorbeeld uit 'n vergelyking van

ISSN 1609-9982 = VERBUM ET ECCLESIA Jrg 22 (1) 2001 
die kommentaar op Romeine met dié op die boek Rut. Laasgenoemde het die diskoersanalise en narratologiese metodes as uitgangspunt vir sy verklaring van Rut gebruik, terwyl die Romeinebrief 'n vers-vir-vers uitleg is met baie aandag aan dogmatiese sake. Gevolglik vind ons in hierdie reeks iets van 'n voorbeeld van die ontwikkelingspatroon van eksegese in Suid-Afrika gedurende die afgelope 60 jaar.

\subsection{Kommentaar op die Bybel (vanaf 1948)}

In 'n voorgenome reeks getiteld Kommentaar op die Bybel, uitgegee deur J L van Schaik en onder redaksie van S du Toit, E P Groenewald en J H Kritzinger, verskyn E P Groenewald se Die Evangelie volgens Markus in 1948. Hierdie boek sou vir meer as 20 jaar teologiese studente, predikante en lidmate begelei in die verstaan van die Markus-evangelie.

Gesien in die lig van die nadraai van die Du Plessis-stryd (hoogtepunt in 1932) en die leerbesluite van die Vrystaatse kerk in 1928, is hierdie boek 'n belangrike kommentaar vir sy tyd. Prof Groenewald huiwer nie om die sinoptiese vraagstuk te bespreek nie en doen voorspraak vir 'n tweebronne-hipotese waarin die Q-bron 'n belangrike rol speel (Groenewald 1948:12). Opvallend is sy deeglike taalbesprekings, sy aansluiting by Ou-Testamentiese en Nuwe-Testamentiese tekste en die vroomheid wat uit sy werk straal.

Hierna is nog 'n kommentaar op Hebreërs (deur P J J S de Klerk) gepubliseer, maar ongelukkig het die reeks nie verdere publikasies opgelewer nie.

\subsection{Die Bybel met Verklarende Aantekeninge (1958-1959)}

Hoewel die vertaling van die Bybel in Afrikaans al in 1933 voltooi is, is daar eers in 1953, na die verskyning van die hersiene uitgawe daarvan, begin met die beplanning van 'n Afrikaanse Bybel met verklarende aantekeninge. Die inisiatief is geneem deur die Verenigde Protestantse Uitgewers. Die sameroeper van die redaksiekommissie was ds J Norval Geldenhuys wat saam met 31 medewerkers bydraes gelewer het. Die eerste twee volumes verskyn in 1958 en die derde in 1959. Die Bybelteks verskyn bo-aan elke bladsy en die kommentaar onderaan. Die doel was dat dit "'n studiebybel vir die individuele gelowige" (Geldenhuys 1958:VII) sou wees.

In die "Woord vooraf" word dit benadruk dat "in ooreenstemming met die belydenis van die Hollands-Afrikaanse Kerke 'n behoudende en tegelyk wetenskaplik verantwoorde standpunt" gehandhaaf is. Daar is "so nou moontlik by die Afrikaanse Bybelvertaling" (dit is die 1933vertaling) aangesluit. 'n Medewerker moes 'n teoloog wees "wat minstens 'n BA-graad in Semitiese tale of Grieks besit". Die redaksie het die werk van medewerkers nagegaan en met opmerkings teruggestuur vir wysigings. Tog is medewerkers toegelaat om "binne die perke van die reëls ... die stempel van die individuele medewerker" af te druk (Geldenhuys 1958:VIII-IX).

Dit was 'n monumentale publikasie vir daardie tyd. Daar is heelwat aandag gegee aan variante vertalings en alternatiewe tekslesings. Dit word gemotiveer op grond van die wye vertaalmoontlikhede van sommige woorde, vooruitgang van die taalwetenskap en nuwe insigte op grond van argeologiese vondse. In die kommentaar word baie klem gelê op die verband met ander dele van die Bybel deur middel van baie teksverwysings en op taalkundige en woordverduidelikings. Die bedoeling was om die Bybel binne sy eie konteks te verduidelik.

Getrou aan die uiteenlopende vertrekpunte van die medewerkers, toon die inhoud tekens van 'n oorgang vanaf behoudendheid of selfs fundamentalisme na ' $n$ meer kritiese lees van die teks. Tog is daar nog baie opvattings wat vandag in die algemeen - veral ten opsigte van die Ou Testament - nie aanvaar word nie:

Volgens die bewerker van Genesis (P F D Weiss) dui Genesis 3:15 op 'n stryd "tussen die duiwel en Christus" (Geldenhuys 1958:10). Hoewel die Pentateugvraagstuk nie bespreek word nie, beklemtoon die medewerker dat Moses nie die skrywer van die eerste vyf boeke kon gewees het nie. Daarteenoor sê die verklaarder van Eksodus (S J du Plessis) dat sekere dele van die boek aan Moses toe te skryf is, terwyl die bewerker van Deuteronomium (J H Kroeze) meen hierdie boek is grotendeels Moses se werk.

Oor die Rigters skryf die verklaarder (E S Mulder) "Uit Handelinge 13:20 weet ons dat die tydperk wat die rigters oor Israel regeer het, 450 jaar geduur het" (Geldenhuys 1958:543). By die boek Job vind die algemene redakteur dit nodig om 'n toevoegsel tot die inleiding te skryf waarin hy beklemtoon dat Job op Christus wys (Geldenhuys 1958b:1012). Die uitdrukking לדוד (leDavid) word op grond van die byskrifte as "deur Dawid" verstaan. Psalm 2 "sien ongetwyfeld op die Messias" (S du Toit in Geldenhuys 1958b:1095) en Psalm 110 "is direk Messiaans" sodat die historiese aanleiding op die agtergrond verdwyn en "die Christus direk voor ons verskyn" (S du Toit in Geldenhuys 1958b:1275). Psalm 51 is deur Dawid geskryf, maar die laaste twee versies is 'n latere toevoeging. Hoewel Hooglied as liefdesliedere beskou word, is dit tog ook tipe van Christus en sy gemeente ( $\mathrm{J} \mathrm{H}$ Kroeze in Geldenhuys 1958b:1447). Jesaja word in vier dele verdeel. Jesaja 52-53 "vorm die hoogtepunt en in sekere sin die dieptepunt van die Ou-Testamentiese Messiasverkondiging" (P A Verhoef in Geldenhuys 1958b:1561). Die boek Daniël "is nie bedoel om werklike feite mee te deel nie" (B Gemser en S du Toit in Geldenhuys 1958b:1858). T F J Dreyer verklaar Jona egter asof dit 'n historiese gebeurtenis was.

ISSN 1609-9982 = VERBUM ET ECCLESIA Jrg 22 (1) 2001 
Hierdie publikasie moet beoordeel word teen die agtergrond van sy tyd: Akademici moes nog die nou paadjie loop tussen die Europese kritiese lees van die Bybel enersyds en die fundamentalistiese nadraai van die Du Plessis-stryd andersyds. Daarby het die opkoms van Afrikaner nasionalisme ook ' $n$ bepaalde invloed uitgeoefen op die verstaan van die Bybel. Gesien teen hierdie agtergrond, het hierdie drie volumes 'n besondere invloed uitgeoefen op die verklaring van die Bybel onder Afrikaanssprekendes.

\subsection{Die Teologiese Boekreeks (vanaf 1965)}

Gedurende die sestigerjare het die Verenigde Lutherse Seminarie in die destydse Suidwes-Afrika en die Teologiese Seminarie van die Evangeliese Broederkerk in Suid-Afrika hierdie reeks die lig laat sien. Benewens kommentare op Genesis (1966), Hosea (1966) en die Brief aan die Galasiërs (1965), het die reeks ook boeke oor 'n verskeidenheid ander aspekte van die teologie ingesluit.

Die merkwaardige van hierdie boeke is dat die skrywers nie oorspronklik Afrikaanssprekend was nie. Die drie kommentare is almal deur Theo Sundermeier geskryf. Dit is gebaseer op lesings wat hy in die seminarium te Otjimbingwe gelewer het. Die doel was om lidmate te begelei om die "steeds toenemende heidendom" en "die groot gevaar van heidense gebruike en praktyke" in die gemeentes van sy kerk te bestry (Sundermeier 1966:5).

Hierdie publikasies verdien vermelding op grond van die volgende sake: Eerstens omdat buitelanders dit in Afrikaans geskryf het. Dit laat 'n mens gou die taalkundige foute vergewe. Tweedens omdat dit van die eerste kommentare in Afrikaans is wat die histories-kritiese benadering van die Duitse teologie aan die Afrikaanse lesers bekend gestel het. Derdens is dit die eerste kommentare in Afrikaans wat nie net wil verduidelik wat die teks beteken nie, maar ook wat dit vir vandag wil sê. Daarmee word dit die baanbreker op die gebied van aktualisering in ons taal. Vierdens is die teks maklik leesbaar en is die bladuitleg leservriendelik.

Alhoewel 'n mens vandag heelwat kritiese anmerkings op die inhoud sou kon opper, moet hierdie reeks se baanbrekersrol waardeer word.

\subsection{Die Verklarende Bybel (1989)}

In 1989 publiseer Lux Verbi 'n Bybel met verklarende aantekeninge onder die naam Die verklarende Bybel. A $\mathrm{H}$ van $\mathrm{Zyl}$, wat 'n hele aantal boeke self verklaar het, was die hoofredakteur. Daar was altesaam 47 medewerkers uit ses verskillende Afrikaanse universiteite.

Die bundel bevat ' $n$ inleiding tot die Bybel, 'n chronologiese lys van historiese en Bybelse gebeurtenisse, visuele uitbeeldings van lite- ratuursoorte in die Bybel en verskeie kaarte. Die doel was om "veral deur die nodige agtergrondinligting die Bybelleser in staat ... [te] stel om die Bybel beter te verstaan" (Van Zyl 1989:VII). Dit is "as deurlopende teks" aangebied. Die boek bevat baie informasie en baie teksverwysings wat verband hou met die saak ter sprake.

Die verklaring vertoon 'n duidelike verskuiwing na 'n meer historiese en selfs histories-kritiese hantering van die teks soos die volgende voorbeelde illustreer: Daar word afgestap van die ou Mosaïese outeurskap van Genesis en gesê dat die boek 'n lang groeiproses deurloop het. Genesis 1 word verbind aan 'n priesterlike outeur en Genesis 2-3 aan 'n profeet. Genesis 3:15 word nie meer as die "moederbelofte" beskou nie en om dit as 'n direkte voorspelling van die Christus-Satan stryd te sien, is 'n Nuwe-Testamentiese afleiding. Numeri het meer as een skrywer gehad en bestaan uit "verskillende literêre 'lae' wat saamgevoeg is" (J H van Schalkwyk in Van Zyl 1989:148). Deuteronomium is nie 'n boek deur Moses nie, maar 'n boek oor Moses.

Die rigtertyd het ongeveer 250 jaar geduur (1250-1000 vC). Die uitdrukking לדוד (leDavid) in die Psalms het verskillende betekenisse en kan nie konsekwent met "deur Dawid" verstaan word nie. Psalm 2 gaan oor 'n koning "wat pas die troon in Jerusalem (Sion) bestyg het" (Van Zyl 1989:590). Psalm 110 moet gelees word teen die agtergrond van Salomo se troonsbestyging en het eers met die loop van tyd 'n Messiaanse betekenis gekry. Hooglied bied "geen aanduiding dat dit 'n ander betekenis het as die voor-die-hand-liggende tema van die liefde tussen man en vrou nie" (D S R du Toit in Van Zyl 1989:733). Jesaja word in twee dele verdeel, terwyl Jesaja 52-53 oor 'n dienaar praat wat die volk "nie gereken het vir wat hy was nie" en wat die Nuwe Testament op Jesus betrek het (J L Helberg in Van Zyl 1989:797). Die boek Daniël kon oorspronklik deur Daniël geskryf gewees het, maar is later saam met sy visioene (Dan 7-12) deur 'n latere skrywer verwerk. Die boek Jona is “"n voorbeeldvertelling amper soortgelyk aan 'n gelykenis" (J H Potgieter in Van Zyl 1989:1011). Aangaande die sinoptiese vraagstuk word klem gelê op die Q-bron en Markus as die bronne vir Matteus en Lukas. Al die Pauliniese briewe word aan Paulus toegeskryf, behalwe die een aan die Kolossense waaroor daar onsekerheid bestaan.

Hierdie hantering van die pauliniese vraagstuk is tekenend van die meer behoudende uitgangspunt van E P Groenewald. Tog het daar onder invloed van $A \mathrm{H}$ van $Z y l$ 'n groot verskuiwing na 'n meer histories-analitiese benadering plaasgevind. Dis veral sy benadering (naamlik die gebruik van die kritiese wetenskap, maar met die handhawing van die gesag van die Bybel) wat vir 'n lang tyd invloed op sy studente en in die kerk uitgeoefen het (Le Roux 1993:141-2). 


\subsection{Kommentaar op die Nuwe Testament: Struktuur, Uitleg, Boodskap (vanaf 1990)}

Hierdie reeks, uitgegee deur Lux Verbi en met H J B Combrink as redakteur, is die resultaat van 'n nuwe beklemtoning wat alreeds in die sewentiger-jare in Suid-Afrika ontwikkel het. Dit is naamlik 'n teksimmanente invalshoek wat meer konsentreer op die teks soos dit is sonder om veel aandag aan die historiese dimensie te gee. Dis 'n metode wat alreeds in W S Prinsloo se kommentaar op Rut in die "Swartband-reeks" sterk na vore gekom het. Maar nou word dit 'n uitgangspunt vir 'n hele reeks. Die klem val op die diskoersanalise, insluitend die indeling van die Griekse teks in cola en, in die geval van Lukas, ook die narratiewe ontleding.

Ongelukkig het die reeks net drie titels opgelewer, naamlik: Die brief aan Jakobus (P P A Kotzé, 1990), Die brief aan Filemon (J H Roberts, 1992) en Lukas in drie volumes (I J du Plessis, 1995). Die staking van die publikasies is 'n groot verlies, aangesien dit 'n vergestalting verteenwoordig van 'n eksegetiese benadering wat grootliks eie aan Suid-Afrika is.

\subsection{Die Woord vir die Mense (vanaf 1992)}

Dis 'n reeks uitgegee deur Orion, onder redaksie van Neels du Plooy. Die bedoeling was om 'n populêre reeks vir lidmate en ernstige lesers van die Bybel beskikbaar te stel. Bundels wat gepubliseer is, is oor Hosea (P Kruger, 1992), Matteus (S J Joubert, 1994), Daniël (C le Roux, 1995), Maleagi (S D Snyman, 1995), die Evangelie van Johannes (J A du Rand, 1995), die briewe aan die Kolossense en Filemon (J H Roberts, 1997) en Hooglied (D W de Villiers, 1997). Ongelukkig het verdere publikasies nie verskyn nie omdat die uitgewer opgehou het om te bestaan.

\subsection{Die Bybel in Praktyk (1993)}

Die Bybel in Praktyk is 'n publikasie van Christelike Uitgewersmaatskappy met Wil Vosloo en Fika J van Rensburg as die redakteurs, met 'n totaal van 12 medewerkers. Die Life Application Bible van 1991 het gedien as stimulus vir 'n soortgelyke boek in Afrikaans. Sommige aspekte van die Life Application Bible, soos kaarte en rubrieke is nagevolg, maar die inhoud is meestal heeltemal nuut oorgewerk. Die meeste medewerkers het ' $n$ eie selfstandige verklaring, gebaseer op die grondtekste en in die lig van die nuutste verklaringsmetodes gelewer.

Kenmerkend van hierdie eenvolumekommentaar is dat dit 'n studiebybel wil wees. Met die jongste weergawe van die Afrikaanse vertaling van die Bybel bo-aan elke bladsy afgedruk, wil die boek lesers deur die teks begelei tot beter verstaan van die Bybel. Dit bevat 'n kruisverwysingsisteem, karaktersketse, diagramme en rubrieke, variante tekslesings, kaarte, 'n tematiese konkordansie en allerlei insiggewende bylaes. Aan die begin van die verklaring van elke Bybelboek is daar ' $n$ tydtabel, 'n samevatting van belangrike feite oor die boek, 'n oorsig, sketsplan en 'n opsomming van die temas in die boek. Al hierdie inligting maak dit 'n handige hulpmiddel by die lees en studie van die Bybel. Dit wil nie net verduidelik wat die teks beteken hét nie, maar veral wat dit vir vandag in die daaglikse praktyk wil sê. Vandaar die naam.

Die publikasie verteenwoordig 'n breuk met sekere opvattings van vroeër en probeer om die resultate van die eksegetiese metodes soos teen 1990-93 in gebruik, op die teks van toepassing te maak. Eksegeties is dit 'n voortsetting van die uitgangspunte van die Verklarende Bybel. Die volgende steekproef toon die standpunte oor etlike verskilpunte in die verlede:

Die boeke van die Pentateug is deur 'n groot aantal skrywers oor 'n lang tyd geskryf. Genesis 3:15 is nie 'n "moederbelofte" nie en is eerder "die aankondiging van 'n meedoënlose stryd tussen die mens en die Bose", met die kruisdood van Jesus as die hoogtepunt en oorwinning oor die Bose (W Vosloo in Vosloo \& Van Rensburg 1993:14-15). Moses het nie Deuteronomium geskryf nie, maar dit het in die tyd van koning Josia ontstaan. Die rigtertyd was tussen 1200-1020 vC. לדוד (IeDavid) kan bloot daarop dui dat die lied "in die Dawidsbundel opgeneem is" (J Burden in Vosloo \& Van Rensburg 1993:757). Psalm 2 dui op 'n aardse Dawidsafstammeling, wat in Nuwe-Testamentiese tye op Jesus van toepassing gemaak is. Dit geld ook van Psalm 110 en ander "messiaanse psalms". Dawid kon nie Psalm 51 geskryf het nie, want in sy tyd "was die mure van Jerusalem nie vervalle" soos 51:20 vermeld nie (J Burden in Vosloo \& Van Rensburg 1993:800). Hooglied handel oor die liefde tussen man en vrou en Salomo het dit nie geskryf nie (J Burden in Vosloo \& Van Rensburg 1993:954). Die boek Jesaja bestaan uit drie dele uit verskillende tye en die dienaar van Jesaja 52-53 is "Ballingskapsisrael" (G Prinsloo in Vosloo \& Van Rensburg 1993:1039). Die boek Daniël het sy finale vorm eers in $165 \mathrm{vC}$ tydens die bewind van Antiogus IV Epifanes gekry en beskryf die geskiedenis tot op Antiogus IV. Die boek Jona het tussen 500 en $333 \mathrm{vC}$ ontstaan en is 'n verhaal oor 'n profeet.

\subsection{Verwysingsbybel - 1983-vertaling (1998)}

Die Verwysingsbybel is 'n produk van die Bybelgenootskap van SuidAfrika. 'n Groot aantal medewerkers (wie se name nie genoem word nie) het deelgeneem aan die skryf van die basiese manuskripte, maar 'n redaksiekomitee het oor etlike jare dit oorgewerk en afgerond. Band 1 bevat die jongste hersiene Bybelteks met aantekeninge op die onderste deel van elke bladsy.

ISSN 1609-9982 = VERBUM ET ECCLESIA Jrg 22 (1) 2001 
Die oogmerk met hierdie publikasie is om "'n Studiebybel wat in die eerste plek 'n Verwysingsbybel is" te wees. "Dit het ten doel om aan die leser by wyse van voetnote (Band 1) asook 'n woordelys, 'n lys van plekname en 'n tematiese kernkonkordansie (Band 2) inligting oor die inhoud en agtergrond van die Bybel te gee" (Verwysingsbybel 1998:vii).

Daar is ongetwyfeld baie tyd, finansies en kragte bestee aan die finale produk. Daarom is dit jammer dat die gebruikerskring baie klein is. 'n Elektroniese weergawe is in produksie en sal waarskynlik dit vir meer lesers toeganklik maak. Dit geld veral Band 1 wat die voetnote bevat. Dit is informasie wat meestal net belangrik is vir persone wat 'n intensiewe studie van die Bybelteks wil maak. Die woordelys, plekname en tematiese konkordansie van band 2 kan wel vir nie-teoloë van groot waarde wees.

Die publikasie is dus nie eintlik 'n kommentaar op die Bybel nie, maar 'n hulpmiddel wat bepaalde inligting verskaf wat van waarde kan wees vir ' $n$ ernstige studie van die Bybelteks en by die skryf van 'n kommentaar.

\subsection{Die Bybellennium Eenvolumekommentaar (1999)}

Die kommentaar, uitgegee deur Christelike Uitgewersmaatskappy, is die produk van 29 kenners van die Ou en Nuwe Testament onder redaksie van Wil Vosloo en Fika J van Rensburg. "Dit is gerig op Bybellesers wat soek na geldige en oorwoë antwoorde op eietydse vrae oor die Bybel en die aktualiteit daarvan vir ons tyd ... vir predikante, studente en alle ernstige Bybellesers" (Vosloo \& Van Rensburg 1999:vii). Dit bevat net kommentaar en nie die Bybelteks nie.

Die kommentaar is 'n mengsel van goeie eksegese uit die grondtale en maklik leesbare Afrikaans in kort, kragtige sinne, met die gebruik van narratologie en metafore. In pas met die jongste metodes, verklaar dit nie woord vir woord nie, maar eenhede sodat die leser die sin van die geheel kan verstaan. Maar dit gebeur nie op 'n deklamerende manier nie. Wetende dat daar verskillende verklaringsmoontlikhede bestaan, word byvoorbeeld vier verskillende uitgangspunte vir die verstaan van die boek Jona, en twee maniere waarop Daniël uitgelê kan word bespreek.

Die leser van vandag word by die Bybel, die boek van gister, uitgebring. Daarom is daar enersyds in-diepte verklarings op grys agtergrond (genoem "fokusvensters") waar die jongste kennis oor taal en vertaling, gebruike, geskiedenis en woordgebruik uitgelig word sodat die ou teks meer verstaanbaar word. Andersyds word daar gepoog om die vrae van vandag se Bybellesers in die uitleg in ag te naam. Die aktualisering vir vandag is dus 'n prioriteit. Daarby is 'n bladuitleg gebruik wat lesers nooi om te lees, met maklike verwysings na die Bybelteks deur vetdruk teksverwysings en kernwoorde, asook Bybelaanhalings in kursief. Talle kaarte en kruisverwysings maak die Bybel nog meer verstaanbaar.

Die inleiding op elke boek is uniek. Dit verduidelik die betekenis van die betrokke boek vir vandag en die verband met ander Bybelboeke, asook die ontstaan en wording van die boek en die wêreld van die eerste lesers, insluitend die sosiale en politieke omstandighede van die vroeë lesers. Ten slotte is daar 'n kort beskrywing van die hooftemas van die betrokke boek.

$\mathrm{Na}$ die verklaring van die Bybelboeke volg drie nuttige bylaes. Onder die opskrif "Met een oogopslag deur die Bybel" beskryf 40 artikels verskeie sake wat nie aan ' $n$ bepaalde teksdeel verbind kan word nie. Dit gaan oor sake soos die leefwêreld van die Bybel se mense, die Bybel as gesagvolle boek, die God van die Bybel, die mens, ander wesens in die Bybel, God se gemeente, die Bybel as boek van hoop, en die Bybel vandag. Dan volg 'n lys van vaktaal-terminologie wat onvermydelik in die uitleg gebruik moes word en wat in die teks met 'n asterisk gemerk is. 'n Besondere toevoeging is die Indeks van Aktuele Temas wat in die kommentaar bespreek word.

In die uitleg van die Bybel maak die medewerkers gebruik van die jongste eksegetiese metodes. Daar word gebou op die grammaties-historiese metode (in 'n meer resente vorm), die histories-kritiese benadering (maar met inagneming van die tekorte daarvan) en met erkenning van die gesag van die Bybel. Gevolglik word die resultate van die diskoers-analise, die narratologiese analise en die sosiologiese analise deeglik verantwoord. Maar ook die resepsiekritiek het 'n plek gekry deurdat daar telkens rekening gehou is met die feit dat lesers se interpretasie van bepaalde tekste tot verskillende konklusies kan lei.

\section{UITDAGINGS, KEUSES EN BESLISSINGS}

Sedert die vertaling van die Bybel in Afrikaans het daar dus 'n verbasende aantal kommentare in Afrikaans die lig gesien. By die beoordeling en gebruik hiervan moet in ag geneem word dat die kommentare lewende illustrasies is van die ontwikkeling van eksegetiese beskouings en metodes in Suid-Afrika. Breed gesproke word meestal drie verskillende fases aangedui, naamlik ' $n$ fokus op (1) die outeur, (2) die teks en (3) die leser van die Bybel (Du Toit 1994:533-4). Hierdie ontwikkeling is duidelik merkbaar wanneer die publikasies met mekaar vergelyk word.

Dis natuurlik baie maklik om kritiek te lewer op enige kommentaar, want dis onmoontlik om 'n kommentaar te skryf wat voldoen aan die vereistes van die verskillende gebruikers daarvan. Ten einde egter ' $n$ kommentaar objektief te beoordeel en te gebruik, moet die tyd waarin en omstandighede waartydens dit geskrywe is deeglik in ag geneem word. Maar daarby moet die keuses waaroor die uitgewer en skrywers van 'n

ISSN 1609-9982 = VERBUM ET ECCLESIA Jrg 22 (1) 2001 
kommentaar beslissings moet neem ook verstaan word. Daarom is dit gepas om vanuit die hoek van skrywer en uitgewer van kommentare na die saak te kyk. Die volgende dinge vra vooraf-beslissings:

1 Moet dit 'n reeks wees of liewers 'n een- of tweevolume kommentaar? 'n Reeks hou die voordeel in dat medewerkers meer breedvoerig op die verklaring kan ingaan. In so 'n geval moet daar geen twyfel wees nie dat die reeks 'n genoegsame afset sal hê wat dit finansieel moontlik maak vir 'n uitgewer om daarin te belê en dat medewerkers beskikbaar sal wees om dit te voltooi. Die geskiedenis van die afgelope 60 jaar toon egter dat daar nog geen reeks in Afrikaans voltooi kon word nie. Daarom verkies uitgewers een- of tweevolume kommentare met die gepaardgaande risiko van beperkte ruimte.

2 Is dit net vir studente en predikante, of net vir lidmate, of vir albei groepe? Weer eens is die aantal kundiges in Afrikaans so klein dat uitgewers huiwer om bloot tegniese kommentare te publiseer. To dusver was daar ook nie 'n voltooide reeks vir lidmate nie. Die middeweg word verkies, naamlik om vir sowel kundiges as leke te skryf. Dit verg uiteraard fyn oorleg. Dit kan bereik word deur tegnies moeilike sake eenvoudiger te stel en die tegniese detail in afgebakende blokke af te druk.

3 Watter uitlegmetode(s) moet gevolg word, grammaties-histories, histories-krities, diachronies, sinchronies, sosiologies, narratologies? of moet gestreef word na eksegetiese pluralisme? Verkieslik behoort 'n verskeidenheid metodes toegepas word. Tog sal dit wys wees om deeglike navorsing te doen na die beoogde leserskring, waarna spesifieke voorskrifte aan medewerkers in hierdie verband gegee moet word.

4 Moet 'n teks-vir-teks woorduitleg gevolg word, of moet die uitgangspunt 'n hele perikoop wees? Laasgenoemde gee 'n geheelbeeld van die betrokke eenheid.

5 Wat moet 'n verklaarder doen met betrekking tot meer as een verklaring van 'n teks? Wanneer geskryf word vir 'n breër leserskring moet in ag geneem word dat mense van verskillende teologiese tradisies betrek word. Sonder dat die medewerker sy/haar eie standpunt prysgee, moet die ander verklaringsmoontlikhede ook aandag geniet.

6 Moet die verklaarder net konsentreer op wat die teks beteken het, of moet daar ook leiding gegee word ten opsigte van aktualisering? Dit beteken dat by aktualisering daar uit die teksverklaring antwoord gegee word op eietydse vrae soos die posisie van die vrou, homoseksualiteit, rasseverhoudings, aborsie, die ekologie, die vraag na die historiese Jesus, lyding, spanning, ensovoorts.

7 Hoe moet polariteite soos die almag van God teenoor die goddelike patos hanteer word? Wat moet gedoen word met die misterieuse en onverklaarbare in die Bybel? Hoe gemaak met botsings tussen wetenskaplike benadering en geloof, gevestigde kerklike tradisie en nuwe insigte?

8 Watter kommunikasieteks moet gebruik word in die geval van 'n kommentaar aan kundiges én leke, aangesien Hebreeus en Grieks ontoeganklik is vir lidmate? Watter vertaling se frasering moet as uitgangspunt gebruik word? Hoe moet vertaalvariasies hanteer word en hoe gemaak met teologiese terme wat vreemd is vir leke?

9 Watter skryfstyl moet gevolg word? Waar eindig gesagsuitsprake en waar begin beskeidenheid? Moet dit bloot beskrywend wees, of is ander maniere soos die narratologiese voorstelling toelaatbaar?

10 Hoe gaan die verhouding Ou en Nuwe Testament in die verklaring hanteer word? Met ander woorde, sal die hele kánon as eenheid funksioneer?

11 Hoeveel medewerkers moet betrek word en watter kriteria gaan gebruik word by die keuse van medewerkers?

12 Hoe sal die bladuitleg lyk, hoeveel teksverwysings moet toegelaat word, hoe kan die kommentaar lesersvriendelik gemaak word?

13 Hoe word die historiese en kultuur-historiese agtergrond in die verklaring ingewerk sodat dit teksverhelderend kan wees?

\section{ONS EN DIE KOMMENTARE}

Die groot verskeidenheid kommentare in Afrikaans tot ons beskikking is 'n voorreg. Die feit dat dit tekenend is van die ontwikkeling van teologiese navorsing gedurende die afgelope 60 jaar bied aan ons ' $n$ dieptedimensie op Skrifuitleg. Die verskeidenheid maak die gebruik daarvan vir verskillende doeleindes soveel makliker. Die feit dat daar kommentare vir sowel predikante as lidmate beskikbaar is, bied nuwe gebruiksmoontlikhede in die bediening. Maar kennis van wat ágter die skrywe van 'n kommentaar lê, help ons om met groter insig te besluit hoe en wat gebruik word vir watter doeleindes.

Waarskynlik was die afgelope 60 jaar die bloeityd vir kommentare in Afrikaans. Die moontlikheid van groot werke vorentoe word om verskillende redes al moeiliker. Tog moet ons die toekoms sien as 'n uitdaging en weë bedink waarlangs ons tog kan voortgaan om in die jare vorentoe die vordering in eksegetiese kennis in kommentare vas te lê en so tot diens te wees vir die kerk en die verstaan van die Bybel. Want daar sal steeds 'n verantwoordelikheid op verklaarders rus om die Bybel verstaanbaar te maak vir elke geslag en tydsgewrig; en om Bybelse 
antwoorde te gee op die vrae waarmee mense op bepaalde tye in die geskiedenis worstel.

\section{Literatuurverwysings}

Du Toit, A B 1994. Die opkoms en huidige stand van die Nuwe-Testamentiese ondersoek in Suid-Afrika: Deel 3 - 'n Kritiese evaluasie. Hervormde Teologiese Studies 50/3.

Geldenhuys, J N 1958. Die Bybel met verklarende aantekeninge. Deel I. Kaapstad: Verenigde Protestantse Uitgewers.

-, 1958b. Die Bybel met verklarende aantekeninge. Deel II. Kaapstad: Verenigde Protestantse Uitgewers.

Le Roux, J H 1993. A story of two ways. Pretoria: Verba Vitae.

Sundermeier, T 1966. Die profeet Hosea. Otjimbingwe: Verenigde Lutherse Teologiese Seminarie.

Van Zyl, A H 1989. Verklarende Bybel. Kaapstad: Lux Verbi.

Verwysingsbybel 1983-vertaling, 1998, Band I en II. Kaapstad: Bybelgenootskap van Suid-Afrika.

Vosloo, W en Van Rensburg, F J 1993. Die Bybel in praktyk. Vereeniging: Christelike Uitgewersmaatskappy.

-, 1999. Die Bybellennium Eenvolumekommentaar. Vereeniging: Christelike Uitgewersmaatskappy. 